\title{
Clinico-epidemiological study of pityriasis rosea in children
}

\author{
Khare $\mathbf{S}^{1}$, Nagar $\mathbf{R}^{2}$, Singh $\mathbf{S}^{3}$ \\ ${ }^{1}$ Dr Sanjay Khare, MD, Associate Professor, ${ }^{2}$ Dr Rahul Nagar, DNB, Assistant Professor, ${ }^{3}$ Dr Suneel Singh Sengar, \\ MBBS, Resident. All are affiliated with Department of Dermatology, Venereology and Leprosy, Mahatma Gandhi \\ Memorial Medical College \& Maharaja Yashwant Rao Holkar Hospital, Indore, MP,India.
}

Address for Correspondence: Dr Rahul Nagar, DNB, Assistant Professor, Department of Dermatology, Venereology and Leprosy, Mahatma Gandhi Memorial Medical College \& Maharaja Yashwant Rao Holkar Hospital, Indore, Emailrahulnagar.doc@gmail.com

\begin{abstract}
Introduction: Pityriasis Rosea (PR) is an acute self limiting disorder, thought to represent a viral exanthema. In majority of cases, the first manifestation is "herald patch" or "mother patch" followed by secondary eruptions. The secondary eruptions appears in crops at an interval of one to two weeks following appearance of herald patch and run parallel to the line of skin cleavage, and mostly appears on the trunk and proximal portion of extremities. Method: A prospective cohort study on the clinico-epidemiological pattern of PR in participants of age group below 15 years was performed over a period of three years. Results: a total 782 patients with clinical diagnosis of PR were treated at our OPD, among them 73 patients fulfilled the study criteria and hence were analyzed and reported here. Out of these $39(53.4 \%)$ were male and 34(46.6\%) were female child. Frequency of PR was highest among age group 11 to 15 years (57.5\%), followed by $35.6 \%$ in age group 5 to 10 years and was lowest among group below 5 years of age (6.9\%). Pruritus was found in $53(72.6 \%)$ patients. Seasonal variation was evident, with highest incidence in summer season, followed by winter and rainy season. Conclusion: in children incidences of PR increases with the age, it was slightly higher in males and was more common during summer season. PR was found to be more commonly associated with upper respiratory tract infections in children as compared to adults, however disease was found to run a similar course as in adults.
\end{abstract}

Key words: Pityriasis Rosea; Atypical; Childhood; Epidemiology

\section{Introduction}

Pityriasis Rosea (PR) is an acute self limiting disorder, thought to represent a viral exanthema [1]. The distinctly programmed clinical course, lack of recurrence for most of the patients, seasonal variation, and clustering of cases provide evidence in favor of an infective etiology, probably viral. However a conclusive infectious cause has not yet been identified [2].

In majority of cases, the first manifestation is "herald patch" or "mother patch" followed by secondary eruptions. The secondary eruptions appears in crops at an interval of one to two weeks following appearance of herald patch and run parallel to the line of skin cleavage, and mostly appears on the trunk and proximal portion of extremities [3]. All the eruptions usually

Manuscript received: $8^{\text {th }}$ Nov 2015

Reviewed: $20^{\text {th }}$ Nov 2015

Author Corrected: $30^{\text {th }}$ Nov 2015

Accepted for Publication: $14^{\text {th }}$ Dec 2015 heals within 6 to 8 weeks. Classical PR has "Christmas tree", "inverted Christmas tree", "fir tree" and "parallel to the ribs" pattern. Atypical PR may be defined as cases with absent herald patch, or localized variants of $\mathrm{PR}$, or inverse PR and papulo-vesicular PR [3]. Incidence of PR has global distribution, where highest incidence of PR are reported during winter season in temperate zones[4]; while maximum incidences in tropical countries occurs during the hot dry months of the year [5]. In different studies the incidence of PR was found to range between 0.39 - 4.80 per 100 dermatology patients [6]. Cohen [7] reported an incidence of $12.8 \%$ among children, however the disease affects both the sexes equally [8]. Similarly, susceptibility to the disease appears not to be influenced by race or genetic framework [9]. Treatment options includes emollients, topical corticosteroid and oral antihistaminic. Although mostly asymptomatic and selflimiting, the presence of skin eruption results in 
considerable anxiety among patients with PR and parents of affected children. The post inflammatory hyperpigmentation may result in significant cosmetic concern, however PR resolves completely without any sequel [10].

We have planned a study to acquire and analyze the data regarding PR in children, a prospective cohort study was conducted over a period of three years. PR related clinical and demographic data were collected and analyzed in this set of population.

\section{Method}

Setting and design: A prospective cohort study on the clinico-epidemiological pattern of PR was conducted in the Out Patient Unit of Department of Dermatology, Venereology \& Leprosy; Mahatma Gandhi Memorial Medical College \&Maharaja YashwantRao Holkar Hospital, Indore, India; during a period from November 2012 to October 2015. During this period a total of 153,316 patients were received at our OPD, out of which 73 cases qualified for the analysis.

Participants and data collection: Patient below 15 years of age with clinical diagnosis of PR were included. Whereas, patients with PR like eruption occurring due atopic dermatitis, seborrheic dermatitis, pityriasis lichenoids chronica, parapsoriasis, guttate psoriasis, irritant and allergic contact dermatitis, erythema multiforme, viral maculopapular or vesicular exanthemes, secondary syphilis as well as eruption lasting for more than four months and eruption with doubtful clinical diagnosis were also excluded.
History was obtained from parents, and wherever possible from the child as well. Informed consent from the guardians of the participants were obtained prior to recruitment. Questions regarding detailed medical history, drug history, growth parameters, immunization history were asked. Complete clinical examination was carried out and recorded giving special emphasis to the onset, evolution, duration, symptoms, systemic features, recurrence, history of contact, presence of herald patch and associated factors such as socioeconomic status, use of new clothing, along with epidemiological data, were recorded in the proforma. Distribution of the lesions was classified into four groups based on a modification of Gelmetti et al [11]. Face and trunk involvement was classified as central, axillary and inguinal region involvement was classified as inverse, upper and lower extremity involvement was classified as peripheral, and when both trunk and extremities were involved, the distribution was classified as diffuse.

Laboratory investigations in the form of routine blood $\&$ urine examination, VDRL, skin scrapings and $10 \%$ potassium hydroxide mount for fungus identification or skin biopsy for histopathological examination were performed wherever found appropriate. Participants with inconclusive diagnosis following laboratory investigations were also excluded.

Statistical analysis: For analysis and presentation descriptive statistical methods were used, whereas mean, standard deviation have been calculated for continuous variable. The Student-t test was used to compare the annual incidences, which was performed on Graphpad Prism 6.0 software. Microsoft Excel 2010 for Windows was used for other statistical calculations.

\section{Results}

During the study period a total 153,316 patients attended our OPD, among them 90,170 were males; 63,146 were females. The total number of patients of PR was 782 patients with clinical diagnosis of PR were received at our OPD, among them 73 patients fulfilled the study criteria and hence were analyzed and reported here. Out of these 39 were male child and 34 were female child, there was slightly male preponderance in ratio of 1.14:1 [table 1]. The age of patients ranged from 11 months to 15 years. Frequency of PR was highest among age group 11 to 15 years (57.5\%), followed by $35.6 \%$ in age group 5 to 10 years, and was lowest among group below 5 years of age $(6.9 \%)$ [table2]. Pruritus was found in 53(72.6\%) patients [table 1]. Seasonal variation was evident, with highest incidence in summer season (total 37), followed by 21 in winter season and least in rainy season (15) [Figure 1]. There was history of having worn new garments among 2 patients prior to the onset of illness. History suggestive of preceding upper respiratory tract infection (URTI) was obtained in 61(83.5\%) patients, out of whom 49 and 12 participants had this history within two weeks and six weeks prior to the appearance of first lesion of PR, respectively. Although seven patients had history of prior medicine intake (paracetamol, antihistaminic, ibuprofen and cefadroxyl) but in none of them drug induced PR could be concluded, when assessed using Naranjo Adverse Drug Reaction Probability Scale [9], so we had recorded these participants in usual PR categories according to their clinical variations. The mean interval of onset of lesions and 
presentation to a physician was $14.5(\mathrm{SD} \pm 6)$ days. Presence of herald patch was found in $52(71.2 \%)$ patient; where the most common site of involvement was trunk (44.2\%), followed by upper extremity (26.9\%) and neck (15.4\%) [table 3]. The mean duration between herald patch and secondary eruption of PR in our study was 12.3 days $(\mathrm{SD} \pm 1.8)$, ranging from 7 days to 18 days. The lesion of secondary eruptions varied in size from 0.5 to $3 \mathrm{~cm}$. They were slightly erythematous to light brown, multiple, discrete, oval $(81 \%)$ or round (7\%) plaques with fine and dry scales in center and collarette at periphery in $93 \%$ of patients. The secondary eruptions mainly involve central distribution 51 participants, followed by diffuse distribution 13, and peripheral distribution 6; inverse distribution was found in 3 participants [table1]. Classical Pityriasis rosea (74\%) was the commonest morphological type, other types seen were atypical Pityriasis rosea (26\%) which includes absence of herald patch in 10 participants, localized PR in 4, Inverse PR in 3 and papulo-vesicular PR in 2 [table 4]. The classic Christmas-tree pattern was present in 24 cases (32.8\%). History of clustering of cases among close contacts was recorded in 9 (12.3\%) patients, however this was based on observation and history provided by parents and / or child, hence cannot be confirmed conclusively. Treatment was given in the form of emollient, topical corticosteroid and if required, oral antihistaminic. Forty one $(56.1 \%)$ participants followed up till complete subsidence of their PR eruption. Of these, duration recorded from the history of occurrence to the complete subsidence was within 30 to 60 days in 24 patients, and between 61 to 90 days in 16 patients, and above 90 days one patient. Petechiae and vesicular lesions were seen in 4 and 3 participants, respectively.

Table 1: Clinical feature of patients with Pityriasis rosea

\begin{tabular}{|l|l|l|}
\hline Characteristics & No. of patients(n) & Percentage (\%) \\
\hline Gender & 39 & $53.4 \%$ \\
Male & 34 & $46.6 \%$ \\
Female & & \\
\hline Preceding upper respiratory tract & \\
infection \& Fever & 61 & $83.5 \%$ \\
Present & 12 & $16.5 \%$ \\
Absent & 53 & $72.6 \%$ \\
\hline Pruritus & & \\
\hline Distribution of lesions & 51 & $69.8 \%$ \\
Central & 13 & $17.8 \%$ \\
Diffuse & 06 & $8.3 \%$ \\
Peripheral & 03 & $4.10 \%$ \\
Inverse & & \\
\hline
\end{tabular}

Figure 1: number of cases of Pityriasis rosea seperately plotted for each year of study period

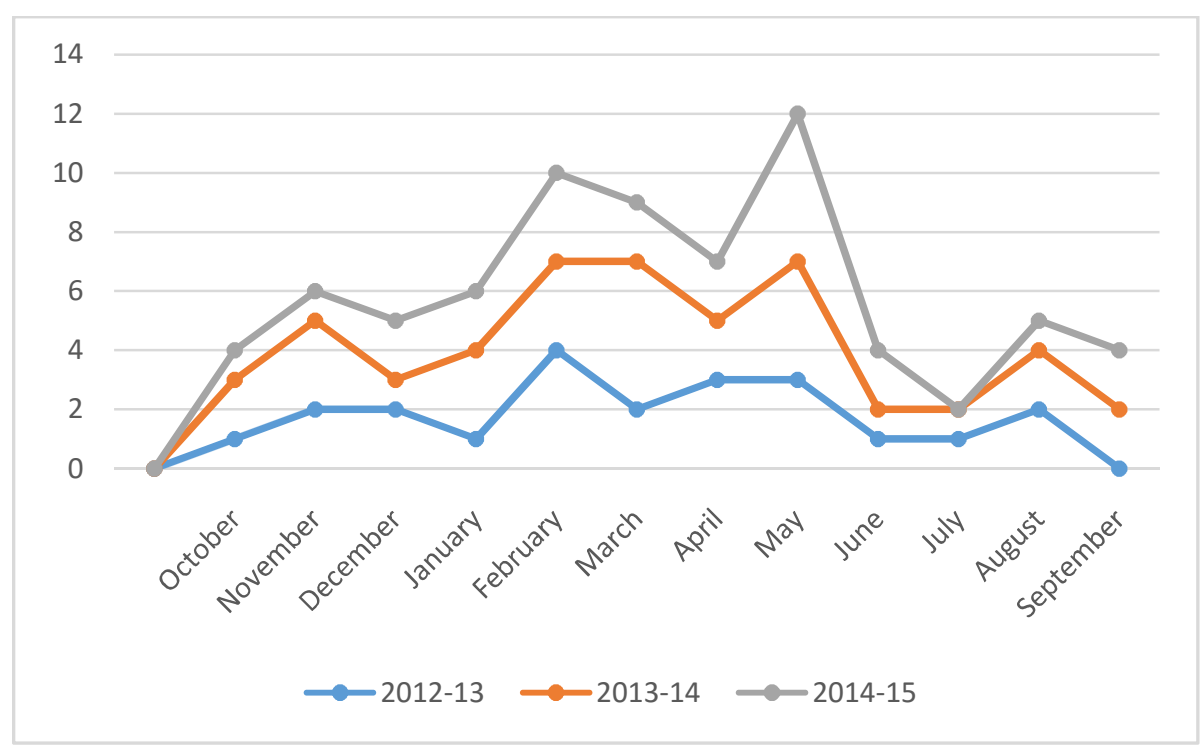


Table 2: Age and sex distribution among patient with Pityriasis rosea

\begin{tabular}{|l|l|l|l|l|}
\hline Age group & $\begin{array}{l}\text { No. of male } \\
\text { patients }\end{array}$ & No. of female patients & Total & Percentage (\%) \\
\hline $0-5$ year & 3 & 2 & 5 & $6.85 \%$ \\
\hline $6-10$ year & 17 & 09 & 26 & $35.6 \%$ \\
\hline $11-15$ year & 23 & 19 & 42 & $57.53 \%$ \\
\hline Total & 43 & 30 & 73 & \\
\hline
\end{tabular}

Table 3: Distribution of herald patches among patients with Pityriasis rosea

\begin{tabular}{|l|l|l|}
\hline Area of involvement & No. of patients $(\mathbf{n = 5 2})$ & \% \\
\hline Trunk & 23 & 44.2 \\
\hline Upper limb & 14 & 26.9 \\
\hline Lower limb & 04 & 7.7 \\
\hline Face & 03 & 5.8 \\
\hline Neck & 08 & 15.4 \\
\hline Total & $\mathbf{5 2}$ & \\
\hline
\end{tabular}

Table 4: Distribution of types of Pityriasis rosea

\begin{tabular}{|l|l|l|}
\hline Type & No. of patients(n) & $\%$ \\
\hline Classical PR & 54 & $74 \%$ \\
\hline Atypical PR & 19 & $26 \%$ \\
1.absence of herald patch & 10 & $13.7 \%$ \\
2.Localized PR & 04 & $5.5 \%$ \\
3.Inverse PR & 03 & $4.1 \%$ \\
4. Papulo-vesicular PR & 02 & $2.7 \%$ \\
\hline
\end{tabular}

Routine hemogram and urine analysis were normal in all patients. Skin scrapings for fungus were negative and VDRL was non-reactive in all cases.

\section{Discussion}

The etiology of PR remains unknown. In our study male to female ratio was 1.14 , which showed nearly equal sex distribution in, which is supported by previous large study in England [8]. Egwin et al reported male preponderance in their study [3] while Chuang $\mathrm{T}$ et al reported female preponderance in their study [13].

The age of maximum incidence is between 10 and 35 years and the disease is considered uncommon in patients younger than 10 years. Our study demonstrates that in children incidences of pityriasis rosea increases with age, which is in agreement to the study performed by Björnberg and Hellgren [14] and by Burch and Rowell [8], who estimated the prevalence of PR in Caucasian children below 10 years of age at $6 \%$ and $10.5 \%$, respectively. Conversely, PR was found more frequent $(26 \%)$ in dark-skinned children in whom facial and scalp involvement (30 vs. $8 \%$ in Caucasian patients) as well as papular lesions and residual hyperpigmentation prevail $[15,16]$. In our study the clinical course of PR in childhood was similar as in adulthood, however Drago F et al [17] found the mean time lapse between the herald patch and the generalized eruption in children (4 days) is very short compared to adults (about 2 weeks), as is the exanthem duration, average duration 16 days in children whereas it lasts about 45 days in adults.

In our series of patients frequency of oropharyngeal lesions was $40 \%$ in age group below 5 years, whereas it was $19 \%$ and $12 \%$ in age group 6-10 years and 11-15 years respectively; a total of 12 patients had oropharyngeal involvement (overall 16\%). Drago et al had shown a higher incidence of $35 \%$ of their patients younger than 10 years, whereas rate much higher $(9 \%)$ than those reported in adult dark skinned [18] and Caucasian (16\%) patients [19].

Conflicting reports are available for seasonal variation in the occurrence of PR. In the temperate regions, it is more frequent during winter months. A higher 
incidence in the winter months was reported by investigators in England, the United States, and Sudan [20]. PR was more common in the rainy season in Lagos, Nigeria [8]. Most of the Indian studies reported higher incidence in winter season [3]. Our study revealed higher incidence in summer season followed by winter and rainy season.

Itching was the commonest symptom reported (72.6\%) in our study, which is close to findings from studies performed by Egwin et al and Mandal et al [3, 21].

In our study, a total of fifty two $(71.2 \%)$ patients presented with herald patch, which was commonly seen on the trunk in $23(44.2 \%)$ patients [table 3]. Similar observation was reported by the earlier study [22]. Immura et al reported absence of herald patch in $20 \%$ cases [23], in our study it is $13.77 \%$.

Egwin et al also reported $10 \%$ patients in whom PR appeared after drug intake [3], however we could not establish the drug as a causative factor in seven participants with history of drug intake, in our study.

In previous study by Turhan AP, $17.5 \%$ cases noted history of upper respiratory tract infection and fever preceding onset of rashes [24]. In our study it is $83.5 \%$, which is much higher than previous studies showing strong correlation between URTI and Pityriasis rosea in children.

The site of secondary eruption has been reported to occur mainly over the trunk, upper extremities and neck [1]; we had observed a similar pattern in our study.

Several previous studies have tried to established a causal role for active systemic HHV-6 and HHV-7 infection in the pathogenesis of PR, based on the detection of HHV-6 and HHV-7 DNA in plasma, mRNA expression and specific antigens in skin lesions of PR patients [ 17, 25]. Also, HHV-6 and HHV-7 plasma viremia, a marker of systemic active infection, was demonstrated in PR and related to the presence of constitutional symptoms [25], but we could not perform such investigation in our patients, owing to unavailability of facilities for such laboratory investigations.

\section{Conclusion}

Results of our study demonstrate that in children incidences of PR increases with age. Where the incidences were slightly higher in males and were more common during summer season. PR was found to be more commonly associated with history of previous URTI in children as compared to adult. Proportion of oropharengeal involvement showed a reducing trend with age. The disease was found to run a similar course as in adults.

\section{Funding:Nil. Conflict of interest: Nil. Permission for IRB: Yes}

\section{References}

1. Jerome M, Parsons, Richmond. Pityriasis rosea update. J Am Acad Dermatol 1986;15(2 Pt 1):159-67. DOI: $10.1016 / \mathrm{S} 0190-9622(86) 70151-5$.

2. Bjornberg A, Tegner E. Pityriasis Rosea, In: Fitzpatrick TB, Freedberg IM, Eisen AZ, et al, eds. Dermatology in General Medicine. 5th ed. New York: McGraw Hill, 1999; 541-6.

3. Egwin AS, Martis J, Bhat RM, Kamath GH, Nanda KB. A clinical study on pityriasis rosea. Indian $\mathbf{J}$ Dermatol 2005;50(3):136-8.

4. Chuang TY, Ilstrup DM, Perry HO, Kurland LT. Pityriasis rosea in Rochester, Minnesota, 1969 to 1978. J Am Acad Dermatol. 1982 Jul;7(1):80-9.

5. Gilbert CM. Traite Pratique des Maladies de la Peauet de la Syphilis. 3 rd ed. Paris:1860; 402.

6. Olumide Y. Pityriasis rosea in Lagos. Int $\mathbf{J}$ Dermatol. 1987 May;26(4):234-6.

7. Cohen EL. Pityriasis rosea. Br J Dermatol. 1967 Oct;79(10):533-7.

8. Burch PR, Rowell NR. Pityriasis rosea--an autoaggressive disease? Statistical studies in relation to aethiology and pathogenesis. $\mathrm{Br} \mathrm{J}$ Dermatol. 1970 Jun;82(6):549-60.

9. Highest AS, Kurtz J. Pityriasis rosea. In Champion RH. Burton JI, Ebling FJG (eds), Textbook of dermatology. 5thedn., Vol.2. Oxford: Blackwell Scientific Publications, 1992:948.

10. Ganguly S. A clinicoepidemiological study of pityriasis rosea in South India. Skinmed. 2013 MayJun;11(3):141-6.

11. Gelmetti C, Rigoni C, Alessi E et al. Pityriasis lichenoides in children: clinicopathologic review of 22 cases. Pediatr Dermatol 1998;15(1):1-6. 
12. Naranjo CA, Busto U, Sellers EM, Sandor P, Ruiz I, Roberts EA, Janecek E, Domecq C, Greenblatt DJ. A method for estimating the probability of adverse drug reactions. Clin Pharmacol Ther. 1981 Aug;30(2):23945.

13. Chuang TY, Ilstrup DM, Perry HO, Kurland LT. Pityriasis rosea in Rochester, Minnesota, 1969 to 1978. J Am Acad Dermatol. 1982 Jul;7(1):80-9.

14. BJORNBERG A, HELLGREN L. Pityriasis rosea. A statistical, clinical, and laboratory investigation of 826 patients and matched healthy controls. Acta Derm Venereol Suppl (Stockh). 1962;42(Suppl 50):1-68.

15. Jacyk WK. Pityriasis rosea in Nigerians. Int $\mathbf{J}$ Dermatol. 1980 Sep;19(7):397-9.

16. Drago F, Broccolo F, Rebora A. Pityriasis rosea: an update with a critical appraisal of its possible herpesviral etiology. J Am Acad Dermatol. 2009 Aug;61(2):303-18. doi: 10.1016/j.jaad.2008.07.045.

17. Drago F, Ciccarese G, Broccolo F, Cozzani E, Parodi A. Pityriasis Rosea in Children: Clinical Features and Laboratory Investigations. Dermatology. 2015;231(1):9-14. doi: 10.1159/000381285. Epub 2015 May 12.

18. Neoh CY, Tan AW, Mohamed K, Sun YJ, Tan SH. Characterization of the inflammatory cell infiltrate in herald patches and fully developed eruptions of pityriasis rosea. Clin Exp Dermatol. 2010
Apr;35(3):300-4. doi: 10.1111/j.13652230.2009.03469.x. Epub 2009 Jul 29.

19. Vidimos AT, Camisa C. Tongue and cheek: oral lesions in pityriasis rosea. Cutis. 1992 Oct;50(4):27680.

20. Ahmed AA. Pityriasis rosea in Sudan. Int $\mathbf{J}$ Dermatol.1986;25(3):184-5.DOI: $\quad 10.1111 / \mathrm{j} .1365-$ 4362.1986.tb02214.x.

21. Mandal SB, Dutta AK. A clinical study of pityriasis rosea. Indian J Dermatol. 1972 Jul;17(4):100-5.

22. Harman M, Aytekin S, Akdeniz S, Inalöz HS. An epidemiological study of pityriasis rosea in the Eastern Anatolia. Eur J Epidemiol. 1998 Jul;14(5):495-7.

23. Imamura S, Ozaki M, Oguchi M, Okamoto H, Horiguchi Y. Atypical pityriasis rosea. Dermatologica. 1985;171(6):474-7.

24. Truhan AP. Pityriasis rosea. Am Fam Physician. 1984 May;29(5):193-6.

25. Watanabe T, Kawamura T, Jacob SE, Aquilino EA, Orenstein JM, Black JB et al. Pityriasis rosea isassociated with systemic active infection with both human herpesvirus-7 and human herpesvirus-6. J Invest Dermatol 2002;119(4):793-7. DOI: 10.1046/j.15231747.2002.00200.x.

\section{How to cite this article?}

Khare S, Nagar R, Singh S. Clinico-epidemiological study of pityriasis rosea in children. Int J Med Res Rev 2015;3(11):1339-1344. doi: 10.17511/ijmrr.2015.i11.243. 